\title{
LA TREVA DE 1418 AMB GRANADA: \\ LA RECUPERACIÓ DE LA TRADICIÓ CATALANOARAGONESA'
}

\author{
ROSER SALICRÚ I LLUCH \\ Institució Milà $i$ Fontanals \\ (CSIC, Barcelona)
}

\section{SUMARI}

1. La Corona d'Aragó i Granada durant el regnat d'Alfons el Magnànim: un canvi en el model de relacions politicodiplomàtiques?- 2. El llegat patern: les treves de model castellà versus les treves catalanoaragoneses.3. La recuperació de la tradició catalanoaragonesa: la influència de Joan Mercader en l'elaboració de la treva.- 4. L'acord de 1418, punt de confluència dels tractats anteriors.

\section{LA CORONA D'ARAGÓ I GRANADA}

DURANT EL REGNAT D'ALFONS EL MAGNÀNIM:

UN CANVI EN EL MODEL DE RELACIONS POLITICODIPLOMÀTIQUES?

Per bé que les relacions politicodiplomàtiques entre la Corona d'Aragó i el sultanat nassarita de Granada al llarg del regnat d'Alfons el Magnànim foren d'una intensitat $i$ riquesa molt més gran del que fins ara havien pogut donar a entendre l'escassa desena de documents que havia

\footnotetext{
'Abreviatures utilitzades: $\mathrm{AA}=\mathrm{Al}$-Andalus; $\mathrm{ACA}=$ Arxiu de la Corona d'Aragó; $\mathrm{AEM}$ $=$ Anuario de Estudios Medievales; ARV = Arxiu del Regne de València; BRABLB = Boletín de la Real Academia de Buenas Letras de Barcelona; C. = Cancelleria; CEM = Cuadernos de Estudios Medievales; $\mathrm{CR}=$ Cartes Reials; f., ff. = foli, folis; $\mathrm{MEAH}=$ Miscelanea de Estudios Árabes y Hebraicos; MR = Mestre Racional; MTM = Miscelánea de Textos Medievales / Miscel-lània de Textos Medievals; $r$ = recto; reg. = registre; $v$ = verso.

"Anuario de Estudios Medievales". 27 (1997)
} 
recollit Giménez Soler en el seu estudi - tan prolífic, en canvi, pel que fa al segle $\mathrm{XIV}^{2}-$, una de les seves principals característiques és no només la quasi total absència de treves o de tractats de pau, sinó també, fins i tot, la manca de voluntat o la manca de consciència de necessitat de negociar-ne i signar-ne.

En una primera meitat del segle XV dominada, a Granada, per Muhammad IX ibn Nasr l'Esquerrà i, a la Corona d'Aragó, per Alfons el Magnànim (i per Joan de Navarra, cap a la fi del regnat del seu germà, almenys pel que fa als contactes amb el sultanat nassarita), les relacions dels dos estats adquireixen una solidesa autònoma que no es vincula o que no necessita ni busca vincular-se a la sanció legal o oficial que podien representar les treves.

Alfons el Magnànim heretà del seu pare, Ferran I, una treva anual que expirà l'abril de 1417 , però quan aquesta s'extingí no arribà a fermar-ne cap més fins ben avançada la dècada dels quaranta. Però aquests tractats tardans, dels que desconeixem el contingut, ja foren deixats a les mans del seu germà Joan de Navarra i estan estretament vinculats a la conflictivitat amb Castella, canalitzada a través de les terres murcianes.

No sabem que, fins aleshores, Alfons hagués arribat a acordar altres pactes que entressin en vigor. N'hi hagué, certament, algunes temptatives, a voltes de tractat, a voltes pròpiament d'aliança, però totes acabaren fracassant, fos, com en el cas de la treva de 1418 que ens ha d'ocupar (que fins $i$ tot quedà registrada a la cancelleria reial ${ }^{3}$ i fou publicada a Valènci$\mathrm{a}^{4}$ ), per l'existència de punts irreconciliables, fos perquè ho impediren, a l'inici dels anys trenta, els sobtats viratges de la política interna granadina ${ }^{5}$.

Però, fins i tot encara que l'absència de treves pogués explicar-se, parcialment, amb el trasllat d'Alfons el Magnànim a Nàpols, és evident que durant el seu regnat s'operà un canvi en la dinàmica de les relacions catalanoaragoneses amb Granada, en el model de les relacions establertes

\footnotetext{
2Vegeu A. GIMÉnEz SOLER, La Corona de Aragón y Granada, "BRABLB" III (1905-1906), pp. 101-134, 186-224, 295-324, 333-365, 405-476, 485-496, "BRABLB" IV (1907-1908), pp. 49-91, 146-180, 200-225, 271-298, 342-375.

${ }^{3}$ ACA, C., reg. 2641, ff. 153v-156r. 1418, juliol, 4. Saragossa, ed. R. SALICRÚ, Relacions..., vol. II, doc. 45.

${ }^{4} \mathrm{ARV}, \mathrm{MR}$, Comptes d'Administració, reg. 39 (1419), f. 166v.

${ }^{5}$ Vegeu-ho, més detalladament i per extens, a R. SALICRÚ I LLUCH, El sultanat de Granada i la Corona d'Aragó, 1410-1458, Barcelona, Publicacions de l'Abadia de Montserrat - CSIC, 1998.
} 
entre tots dos estats, en la visió de les relacions amb Granada i de les qüestions pensinsulars. Perquè l'absència de treves no és pas atribuïble a la impossibilitat d'arribar a acords havent-hi la voluntat de negociar-los, sinó que es relaciona - $\mathrm{i}$ aparentment potser de manera contradictòria - amb una intensificació i afermament dels contactes, sobretot comercials ${ }^{6}$. És deguda, senzillament, a la manca de consciència de necessitat de signar-ne, perquè els pactes deixen de considerar-se imprescindibles per controlar o per evitar els incidents i per garantir l'estabilitat de les relacions, perquè aquestes han assolit una fermesa que els permet desenvolupar-se al marge d'acords interestatals que hagin de protegir-les. Al marge de pactes oficials, Alfons el Magnànim i Muhammad IX de Granada foren capaços de bastir i de mantenir una entente o una quasialiança tàcita, mai formulada, que superà i sobrevisqué a tots els esculls conjunturals.

En aquest sentit, podríem dir que, si bé durant els primers anys del regnat d'Alfons el Magnànim, mentre estigué en vigor la treva de 1416-1417 $i$ fins al fracàs de la de 1418 que ens ocupa, les relacions entre la Corona d'Aragó i Granada continuaren desenvolupant-se o es regiren, almenys a nivell politicodiplomàtic, segons el que podríem considerar el model de

\footnotetext{
'Sobre les relacions comercials de la Corona d'Aragó amb Granada, remeto, a més d'als estudis de J. HinOjOSA Montalvo, Las relaciones entre los reinos de Valencia y Granada en la primera mitad del siglo XV, dins Estudis d'Història de València, València, Universitat de València, 1978, pp. 91-160; IDEM, Las relaciones entre Valencia y Granada durante el siglo $X V$ : Balance de una investigación, dins Estudios sobre Málaga y el Reyno de Granada en el $V$ Centenario de la Conquista. Màlaga, Servicio de Publicaciones de la Diputación Provincial. 1987, pp. 83-111; IDEM, Armamento de naves y comercio con el reino de Granada a principios del siglo XV, dins Andalucía entre Oriente y Occidente (1236-1492). Actas del V Coloquio Internacional de Historia Medieval de Andalucía, Córdoba, Diputación Provincial, 1988, pp. 643-657: IDEM, El Reino de Valencia, frontera marítima entre Aragón y Granada, dins La frontera oriental nazarí como sujeto histórico (s. XIII-XVI). Actas del Congreso. Almeria, Instituto de Estudios Almerienses, 1997, pp. 409-434; o de M. RUZAFA GARCía, La frontera de Valencia con Granada: la ruta terrestre (1380-1440), dins Andalucía entre Oriente, pp. 659672; IDEM, Las relaciones económicas entre los mudéjares valencianos y el reino de Granada en el siglo XV, Relaciones Exteriores del Reino de Granada. IV Coloquio de Historia Medieval Andaluza, Almeria, Instituto de Estudios Almerienses, 1988, pp. 343-381, i IDEM, La Corona de Aragón y Castilla en el Norte de Africa durante el Cuatrocientos, dins Relaciones de la Corona de Aragón con los Estados Cristianos peninsulares (siglos XIII-XV). XV Congreso de Historia de la Corona de Aragón, volum II, Saragossa, Gobierno de Aragón, 1997, pp. 305 314; a R. SALICRÚ I LLUCH, La presència comercial catalanoaragonesa al sultanat de Granada durant el regnat d'Alfons el Magnànim, dins La Corona d'Aragona ai tempi di Alfonso il Magnanimo. XVI Congresso Internazionale di Storia della Corona d'Aragona. Napoli, settembre 1997, en curs de publicació (amb versió en anglès a "Al-Masaq", 10 (1998), en curs de publicació) i, més per extens. a IDEM, Relacions de la Corona d'Aragó amb' el regne de Granada al segle XV (1412-1458), Barcelona, Universidad de Barcelona, 1996 [edició en microformal, vol. I, pp. 671-778.
} 
Dufourcq, que caracteritza les relacions entre cristians i musulmans en base a l'existència d'un permanent estat de guerra ocasionalment interromput per la declaració d'una treva ${ }^{7}$, aquest model, que podria considerar-se vàlid per la Corona d'Aragó del segle XIV i de l'inici del XV en les seves relacions amb Granada i amb el Magrib ${ }^{8}$, o per definir les relacions de Castella amb Granada fins a la fi del sultanat, però que, en canvi, no és o no sembla pas aplicable al model d'expansió genovès a la Mediterrània Occidental ${ }^{9}$, deixa també de ser aplicable, durant el regnat d'Alfons el Magnànim, a les relacions entre la Corona d'Aragó i Granada.

\section{EL LLEGAT PATERN: LES TREVES DE MODEL CASTELLÀ VERSUS LES TREVES CATALANOARAGONESES}

Tanmateix, i com ja he dit, Alfons el Magnànim heretà, a la mort del seu pare, Ferran I, esdevinguda el 2 d'abril de 1416, una treva anual, que s'estenia del 18 d'abril de 1416 fins al 16 d'abril de $1417^{10}$.

\footnotetext{
${ }^{7}$ Vegeu Ch.-E. DufourcQ. Chrétiens et musulmans durant les derniers siècles du Moyen Age, "Anuario de Estudios Medievales" 10 (1980), pp. 207-225.

${ }^{8}$ Vegeu-ho, per exemple, a M.T. FERRER I MALLOL, La frontera amb l'Islam en el segle XIV. Cristians i sarraïns al País Valencià. Barcelona, Institució Milà i Fontanals - CSIC, 1988; M.D. LÓPEZ PÉREZ, Las relaciones comerciales y diplomáticas entre la Corona de Aragón y los estados norteafricanos durante la Baja Edad Media. "Anuario de Estudios Medievales" 20 (1990), pp. 149-169, i IDEM, La Corona de Aragón y el Magreb en el siglo XIV (1331-1410), Barcelona, CSIC - Institució Milà i Fontanals, 1995.

"Sobre el "model" genovès, vegeu, G. PISTARINo, Genova medievale tra Oriente e Occidente, "Rivista Storica Italiana" LXXXI (1969), pp. 44-73; IDEM, Genova e l'Islam nel Mediterraneo occidentale (secoli XII-XIII), "Anuario de Estudios Medievales" 10 (1980), pp. 189-205; IDEM, Commune, "Compagna" e Commonwealth nel medioevo genovese, dins La Storia dei Genovesi. Atti del convegno di studi sui ceti dirigenti nelle istituzioni della repubblica di Genova. 1982. III volume, [Gènova], [1983], pp. 9-28; J.E. RUIZ DOMÉNEC, El sueño de Ulises: la actividad marítima en la cultura mediterránea como un fenómeno de estructura, dins Le Genti del mare mediterraneo. Atti del XVII Colloquio Internazionale di Storia Marittima (1980). Nàpols, Lucio Pironti Editore, 1981, pp. 27-58, i IDEM. Genova e la Spagna nel Basso Medioevo, dins La Storia dei Genovesi. Atti del Convegno di studi sui ceti dirigenti nelle istituzioni della repubblica di Genova. 1984. V volume, [Gènova], [1985], pp. 49-64.

${ }^{10}$ Seguint la dinàmica de les treves anuals que, des de 1413 (i enllaçant amb una de disset mesos que finalitzà l'abril de 1412, signada després de la conquesta d'Antequera), Ferran va signar tot al llarg del seu regnat, hom ja havia suposat, des de Castella, per la coincidència cronològica amb la posterior treva de 1417-1419, que també s'havia conclòs la de 1416-1417, però fins ara no n'hi havia proves documentals (vegeu, essencialment, M. ARRIBAS PALAU, Las treguas entre Castilla y Granada firmadas por Fernando I de Aragón, Tetuan, Centro de Estudios Marroquíes - Editora Marroquí, 1956; J. TORRES FONTES, La regencia de don Fernando el de Antequera y las relaciones castellano-granadinas (1407-1416), [IV. Las treguas],
} 
Des que expirà aquesta treva i fins a la negociació i signatura, després invalidada, de la de 1418, que hauria estat de dos anys, Alfons no establí negociacions per prorrogar-la ni amb Yusuf III ni, després de la mort d'aquest, amb el seu fill i hereu del tron nassarita, Muhammad VIII el Petit, sinó que, sempre que li convingué, féu recurs a la treva castellanogranadina de 1417-1419 i apel·là a la intercessió del seu cosí, Joan II de Castella, i de la regent i mare d'aquest, Caterina de Lancàster ${ }^{11}$.

Inicialment, per tant, Alfons es regí pel que podríem considerar la inèrcia del llegat del seu pare, estretament vinculat a les treves i a la tradició castellana.

Perquè, si bé al llarg del regnat de Ferran d'Antequera les treves que aquest pactà amb Granada incorporaren també la Corona d'Aragó, els acords no foren pas, ni formalment ni a nivell de contingut, treves catalanoaragoneses amb Granada, sinó pròpiament i estricta treves castellanogranadines, signades per Ferran com a regent de Castella i en nom del seu nebot Joan II, que era qui les atorgava, que es feren extensives a la Corona d'Aragó pel fet que Ferran de Trastàmara era, alhora, regent de Castella i monarca catalanoaragonès.

En conseqüència, l'articulat dels tractats que, el 1413-1414, 14141415, 1415-1416 i 1416-1417 abastaren la Corona d'Aragó ${ }^{12}$ era el de les treves castellanes, el mateix que el de la treva de disset mesos de 1410-

\footnotetext{
"MEAH" XXII (1973), pp. 7-59, i IDEM, Las relaciones castellano-granadinas desde 1416 a 1432. I. Las treguas de 1417 a 1426, "CEM" VI-VII, (1978-1979 [1981]), pp. 297-311). Tanmateix, com exposo més detalladament a R. SALICRÚ, El sultanat, pp. 95-100, ha quedat testimoni de la seva signatura a ACA, C., Papers per Incorporar, caixa 45 (sobre de maig de 50 documents). [1416], maig, 26. S.I., ed. R. SALICRÚ, Relacions, vol. II, doc. 17, notícia que, tanmateix, jo mateixa encara desconeixia en redactar Posibilidades de reanudación de la guerra de Granada a finales del reinado de Fernando I de Aragón (1415-1416), dins La Península Ibérica en la era de los descubrimientos (1391-1492). Actas III Jornadas Hispano-Portuguesas de Historia Medieval. Sevilla 25-30 de noviembre 1991, Sevilla, Junta de AndalucíaUniversidad, 1997, vol. II, pp. 1437-1452.

"Vegeu-ho a R. SALICRÚ, El sultanat, pp. 129-135.

${ }^{12}$ Vegeu els tres primers editats a M. ARriBas, Las treguas, docs. 8, $17 \mathrm{i} 18$; pel que fa al darrer, que indubtablement devia reproduir les mateixes cläusules, $j a$ he indicat que fins ara no n'hi havia ni tan sols l'evidència documental de la seva existència.
} 
$1412^{13}$ que Ferran havia signat, després de la presa d'Antequera, i que li havia permès dedicar-se plenament a la consecució del tron catalanoaragonès.

Les treves de Ferran d'Antequera foren concebudes sempre, més que no pas com a paus, com el que podríem considerar treves de guerra, és a dir, acords concertats més amb la mentalitat de suspensió d'hostilitats, de compàs o de parèntesi d'espera per reprendre la guerra, que no pas amb mentalitat de veritable pau, en part perquè les campanyes de l'infant castellà eren molt recents $i$ en part perquè Ferran anhelava i confiava que, en un moment $o$ altre, podria tornar a iniciar les hostilitats ${ }^{14}$.

És evident que les treves ferranianes es gestaren seguint els models i les pautes heretades i repetides, incansablement i quasi monòtona, des del segle XIII, a Castella.

Llur estructura i llurs clàusules i caràcters generals són, exactament, els mateixos que ja presentaven les treves castellanogranadines de la primera meitat del segle XIV, durant el regnat d'Alfons $\mathrm{XI}^{15}$, amb només lleugeres diferències: al marge de la manca de llibertat comercial, que és quelcom conjuntural, en contraposar-les només hi trobem a faltar dues de les seves clàusules genèriques, que no hi són presents pel canvi de conjuntura operat durant el més de mig segle del que Ladero anomena pau insòlita (1350$1406)^{16}$ que separa les paus d'Alfons XI de les de Ferran d'Antequera. Es tracta, en primer lloc, de la clàusula que pretenia que no es reconstruïssin ni reedifiquessin, ni per part de Castella ni per part de Granada, els castells i fortaleses més propers a la frontera i que, a causa de l'estat de guerra, estaven enrunats, en un intent d'aconseguir una terra erma i despoblada que actués com a veritable frontera geogràfica i que permetés detectar amb

\footnotetext{
${ }^{13}$ Del 10 de novembre de 1410 al 10 d'abril de 1412; per bé que el text original no és conegut, la crònica d'Álvar García de Santa María en dóna a conèixer el contingut íntegre, recollit per Carriazo a J. de M. CARRIAZO Y ARROQUIA, Un alcalde entre los cristianos y los moros en la frontera de Granada, "AA" XIII (1948), pp. 65-70, i reprès, posteriorment, per ell mateix. a Crónica Juan II de Castilla, Madrid, Real Academia de la Historia, 1982, pp. 402408.

${ }^{14}$ Sobre aquesta pretensió de Ferran I, que havia començat a cristal-litzar seriosament quan ell morí, vegeu R. Salicrú, Posibilidades

${ }^{15}$ Vegeu-ho a M. GARCÍA FERnÁndez, Las treguas entre Castilla y Granada en tiempos de Alfonso XI, 1312-1350, "IFIGEA" V-VI (1988-89), pp. 135-154, especialment pp. 137-141, o bé, igualment, a IDEM, Andalucía en tiempos de Alfonso XI, Sevilla, Departamento de Historia Medieval, 1987 [edició en microforma], pp. 256-292.

${ }^{16}$ Vegeu M.Á. Ladero QueSada, Granada. Historia de un país islámico (1232-1571), Madrid, Gredos S.A., 1989 (3a. edició revisada i ampliada), pp. 156-165.
} 
facilitat la possible penetració i avançada cap a l'interior de l'enemic ${ }^{17}$. I, en segon lloc, també desapareixen unes de les clàusules més significatives de les treves d'època alfonsina, les que feien referència a les pàries, signe evident del vassallatge granadí, tot i que, aleshores, en els moments en què Castella es trobava en una situació d'inferioritat a causa de les derrotes militars, també podien obviar-se ${ }^{18}$.

Aquestes característiques generals de les treves castellanogranadines, engendrades i repetides des del segle XIII, perpetuades al llarg de la primera meitat del XIV en els acords d'Alfons XI i presents a les de l'infant Ferran, també segueixen apareixent, encara, a la resta de treves conegudes del segle $\mathrm{XV}^{19}$.

Les treves castellanogranadines i, en concret, les ferranianes, essent més treves de guerra o de suspensió d'hostilitats que no pas, pròpiament, tractats de pau, implicaven, d'entrada, que la part introductòria dels acords definís clarament quins eren els límits fronterers del moment, és a dir, els resultants, en el cas de Ferran, de les seves campanyes, i que diversos capítols estiguessin adreçats a garantir-ne l'estabilitat, amb compromís mutu de tots dos regnes.

\footnotetext{
${ }^{17}$ M. García, Las treguas, p. 140.

${ }^{18}$ Ibidem, pp. 140-141

${ }^{19}$ Vegeu, per exemple, la de 1424 a M. ARribas, Las treguas, doc. 19; la de 1439, molt més precisa, a J. AMADOR DE LOS RÍOS. Memoria histórico-crítica sobre las tréguas celebradas en 1439 entre los reyes de Castilla y de Granada, "Memorias de la Real Académia de la Historia" IX (1879), docs. LXXVII i LXXX, pp. 128-131 i 133-137; el que se sap de la de 1443, a J.E. LÓPEZ DE COCA CASTAÑER, Castilla, Granada y la tregua de 1443, dins Estudios de Historia Medieval. Homenaje a Luis Suárez, Valladolid, Universidad de ValladolidSecretariado de Publicaciones, 1991, pp. 301-313; el que se sap de les de 1475 i 1478 , a J. de M. CARriazo y Arroquia, Las treguas con Granada de 1475 y' 1478, "AA" XIX (1954), pp. 317-364 (reeditat a En la frontera de Granada. Homenaje al Profesor Carriazo, vol. I, Sevilla, Facultad de Filosofía y Letras, 1971, pp. 193-236); i, a més, vegeu també J. TORRES, Las relaciones 1417-1426; IDEM, Las treguas con Granada de 1462 y 1463, "Hispania" XXXIII (1963), pp. 163-199; IDEM, Enrique IV y la frontera de Granada (Las treguas de 1458, 1460 y' 1461), dins Homenaje al Profesor Carriazo. Sevilla, Publicaciones de la Universidad, vol. III, 1973. pp. 343-380, i J. de M. CARRIAZO, Un alcalde. L'acord que signà Yusuf ibn al-Mawl el 1431/1432 amb Joan II de Castella té, en canvi, evidentment, un caràcter diferent; vegeu-ho a A. BENAVIDES, Memoria sobre la guerra del reino de Granada y los tratos y conciertos que precedieron a las capitulaciones de la ciudad, "Memorias de la Real Academia de la Historia" VIII (1852), pp. 41-45; M.A. ENAN, Un tratado del siglo XV entre Castilla y Granada, "Revista del Instituto de Estudios Islámicos" II 1-2 (1954), pp. 38-54, i L. SUÁREZ FERnÁNDEZ, Juan II y la frontera de Granada, "Estudios y Documentos. Cuadernos de Historia Medieval" 2 (1954), doc. VI.
} 
Castellans i granadins - i, per extensió, al llarg del regnat de Ferran I, catalanoaragonesos i benimerins ${ }^{20}$ - havien de defensar-se mútuament dels enemics i, uns i altres, havien de barrar-los el pas per llurs reialmes, si convenia per la força de les armes. A més, els tractats preveien que, si alguna vila o lloc s'alçava en contra del seu rei, l'altra part havia d'ajudar-lo a recuperar-lo, o que, si els respectius súbdits ocupaven alguna plaça a l'altra banda de la frontera, els monarques haguessin de restituir-la i no poguessin acceptar-la.

Aquesta mentalitat de parèntesi bèl·lic també feia que el lliure trànsit de persones a una i altra banda de la frontera quedés limitat als alfaquecs que anessin a redimir captius; la resta de súbdits, per entrar al regne veí, necessitaven llicència reial, cosa que limitava o impedia, per tant, la llibertat de comerç.

Els monarques es comprometien a restituir qualsevol súbdit de l'altre que fugís al seu regne, sense protegir-lo ni emparar-lo, però si qui aconseguia fugar-se era un captiu i tenia la sort de poder arribar a les seves terres d'origen, aleshores esdevenia lliure, si bé havia de reintegrar tots els béns que hagués pogut endur-se'n.

Finalment, per dirimir les querelles entre moros i cristians, les treves regulaven detalladament l'existència i el paper del jutge de frontera ${ }^{21}$.

Les treves catalanoaragoneses amb Granada també havien anat adquirint una personalitat pròpia, netament diferenciada de la de les castellanogranadines.

Des de mitjan segle XIII, la corona catalanoaragonesa ja no tenia frontera de contacte territorial directe amb l'Islam i, entre les terres més

\footnotetext{
${ }^{20}$ Les treves castellanogranadines habitualment també es feien extensives al sultanat marínida de Fes, en el que, a la primeria del segle $X V$, Ladero considera una tradició que, en realitat, no tenia importància ( $c f$. M.Á. LADERO, Granada, p. 168). Sobre la inclusió de Fes a les treves tant castellanes com catalanoaragoneses amb Granada, vegeu també l'article de M. ARRIBAS Palau, Los benimerines en los pactos concertados entre Aragón y Granada, dins Actas del primer congreso de estudios árabes e islámicos (Córdoba 1962), Madrid, Imprenta y Editorial Maestre, 1964, pp. 179-188, i el primer epígraf de R. SALICRÚ I LLUCH, L'ambaixada a Fes d'Antoni Queixal i Ramon de Conesa (1413-1414), "Acta Historica et Archaeologica Mediaevalia" 19 (1998), "Ferran d’Antequera i la inclusió del regne de Fes a les treves amb Granada", en curs de publicació.

${ }^{21}$ Vegeu M. García, Las treguas, pp. 135-153; J. de M. Carriazo, Un alcalde..., pp. 66 69, i M. ARribas, Las treguas, docs. 8, 17 i 18. Sobre el jutge de frontera, vegeu, a més, L. SECO DE LuCENA PAREDES, El juez de frontera y los fieles del rastro, "MEAH" VII (1958), pp. 137-140; IDEM, Sobre el juez de frontera, "MEAH" XII (1962), pp. 107-109, i J. TORRES FONTES, El alcalde entre moros y cristianso del reino de Murcia, "Hispania" XX (1960), pp. 55-80.
} 
meridionals de la governació d'Oriola i el regne de Granada, s'hi interposava el regne de Múrcia. Però el regne de Múrcia era un territori tan estret que no constituïa un aïllant segur $\mathrm{i}$, per tant, la meitat meridional del regne de València era constantment amenaçada per les expedicions terrestres; a més, tota la costa catalana i valenciana era oberta al perill d'incursions corsàries sarraïnes. Per això, i com que la frontera era, en definitiva, tot el territori que podia ésser amenaçat per una ràtzia granadina ${ }^{22}$, als segles XIV i XV la major part del País Valencià era considerada, encara, zona de frontera amb Granada ${ }^{23}$, i així ho percebien i manifestaven, contínuament, els seus habitants ${ }^{24}$.

Tanmateix, però, encara que la realitat quotidiana de les gents d'aquestes terres fos la de la vida de frontera i que això condicionés les relacions entre els monarques catalanoaragonesos i els sultans granadins, també és cert que aquesta relació de frontera era una relació que afectava sobretot els aspectes i els contactes humans, i que era a través d'aquests que incidia en les relacions polítiques i diplomàtiques interestatals.

Encara que aquest sentit fronterer de les relacions humanes condicionés les treves catalanoaragoneses amb Granada i els atribuís i permetés adquirir aspectes propis de treves frontereres, equiparables, sovint, en això, a les treves castellanogranadines, la manca de frontera territorial directa els donava, a nivell polític, un caràcter diferent. És evident que les implicacions de l'estat de pau o de l'estat de guerra en les relacions entre la Corona d'Aragó i Granada no eren les mateixes que les de la pau o de la guerra entre Castella i Granada, com a estats físicament veïns i fronterers. La gent de la frontera valenciana podia viure amb la mateixa cruesa que la castellana i murciana els períodes d'hostilitat oberta, a través de les

\footnotetext{
${ }^{22}$ M.T. FERRER, La frontera, p. V.

${ }^{23}$ Vegeu, a més de M.T. FERRER, La frontera..., IDEM, Organització i defensa d'un territor fronterer. La Governació d'Oriola en el segle XIV, Barcelona, CSIC-Institució Milà i Fontanals, 1990.

${ }^{24}$ per ço com és en frontera, specialment de Granada - la mateixa expressió que, extreta de l'Arxiu Municipal de València, encapçala J. HINOJOSA, El Reino, p. 409-, apareix constantment entre la documentació valenciana; vegeu, per exemple, les consideracions sobre el caràcter fronterer d'Oriola que conté la carta adreçada pel consell de la vila a Alfons el Magnànim a l'inici de 1418 (ACA, C., CR Alfons IV, caixa 6, núm. 719. 1418, gener, 17. Oriola) que comento a R. SALICRÚ, El sultanat, pp. 143-145, i que, pels fragments que en cita, ha de ser la mateixa que esmenta, a partir de la documentació oriolana, J.A. BARRIO BARRIO, La frontera marítima en Orihuela durante el reinado de Alfonso V (1416-1458), dins La frontera, p. 439.
} 
incursions i de les malifetes dels almogàvers, dels raptes, de les preses, de les represàlies o dels furts i robatoris. Però, a nivell d'estat, allò que perseguien les treves entre la Corona d'Aragó i Granada i allò que podien perseguir els acords castellanogranadins no era pas el mateix.

En tots dos casos, les treves intentaven proporcionar a la frontera un clima de seguretat i d'estabilitat en les relacions humanes, tant si pensem en la demografia, com en l'economia $i$ en la subsistència dels habitants de frontera, com en les relacions comercials ${ }^{25}$.

En canvi, mentre que una treva entre Castella i Granada buscava garantir la immobilitat física de la frontera i la inexistència de guerra en el sentit més clàssic del terme, una treva entre la Corona d'Aragó i Granada era, per força, una treva més "a distància", i sovint condicionada per l'estat de les relacions castellanogranadines. Per exemple, encara que, en el moment de signar un acord, les treves catalanoaragoneses amb Granada poguessin definir quines eren les possessions granadines i el monarca catalanoaragonès hagués de comprometre's a respectar-les, no hi havia cap necessitat de descriure els límits fronterers ni d'enumerar les fortaleses a una i altra banda de la frontera amb la finalitat de garantir-ne l'estabilitat. Allò que interessava en realitat era, sobretot, guanyar-se i garantir-se el suport logístic de l'altra part, per evitar que pogués aliar-se amb Castella i fer-hi front comú. Les treves catalanoaragoneses amb Granada concretaven, habitualment, l'ajut militar que els dos estats havien de fornir-se mútuament en cas de guerra contra un enemic, que, en el fons, moltes vegades no era altre que Castella. Així, per exemple, si Granada i Castella entraven en guerra, els nassarites impedien que els dos regnes cristians s'aliessin contra ells, s'asseguraven un cert nombre de galeres i, ocasionalment, de contingents terrestres. De la mateixa manera, si eren la Corona d'Aragó i Castella les qui s'enemistaven, catalans i granadins podien combatre conjuntament, per dos fronts, l'enemic.

Per altra banda, la fermesa dels contactes comercials existents entre les terres catalanoaragoneses i el sultanat nassarita, que podem remuntar,

\footnotetext{
${ }^{25}$ Per mitjà de la carta esmentada a la nota precedent, per exemple, els oriolans declaraven que, quan hi havia guerra, la terra es despoblava i la gent no gosava cultivar la muntanya ni gran part de l'horta, ni tampoc treure a pasturar els ramats, mentre que, quan hi havia pau, tot prosperava, es conreaven horta i muntanya i els ramats pasturaven i criaven lliurement $i$ oberta.
} 
almenys, a les darreres dècades del segle XIII ${ }^{26}$, i la importància de la mar com a via de desenvolupament d'aquests contactes feren que, des de ben aviat, les treves incorporessin diverses clàusules per regular el desenvolupament d'aquesta activitat mercantil, molt més concretes i detallades que no pas les clàusules que, a les treves castellanogranadines i en períodes de llibertat de comerç, feien referència als intercanvis, en gran part terrestres $^{27}$.

Per tant, durant el regnat de Ferran d'Antequera els seus súbdits quedaren subjectes a unes condicions que els eren alienes. I tot i que la teòrica restricció de l'activitat comercial, tanmateix viable, no impedí que aquesta se seguís desenvolupant, aquesta concepció diversa produí algunes friccions. La correspondència del batlle general del regne de València, Joan Mercader, n'és un testimoni de primer ordre, ja que durant els anys $1413 \mathrm{i}$ 1414 es produïren un seguit d'incidents piràtics, constants, protagonitzats per castellans amb base a Cartagena que, segons sembla, es dirigien essencialment contra els mercaders valencians que traficaven amb terres musulmanes. Aquests pirates legitimaven la seva actuació al·legant que les naus capturades comerciaven amb els infidels. Encara que el batlle de València i les autoritats municipals no es cansaren de demanar al monarca que hi posés fi, no només per defensar els seus vassalls sinó també per les atribucions que, com a regent, tenia sobre els castellans, l'actitud del rei Ferran fou

\footnotetext{
${ }^{26} \mathrm{~A}$ la darrera dècada del segle XIII ja hi ha constància de diversos guiatges concedits per Jaume II a mercaders sarraïns granadins perquè anessin als seus regnes amb llurs rècules $\mathrm{i}$ mercaderies; vegeu M.T. FERRER, La frontera, p. 50

${ }^{27}$ No puc pas estar d'acord, per tant, i ho comprovarem en analitzar les clàusules de la treva de 1418 en funció de les treves catalanoaragoneses amb Granada conegudes, amb l'opinió d'E. MITRE FERNÁNDEZ, Las relaciones castellano-granadinas en el marco de la política peninsular de Enrique III. Notas para su estudio, "CEM" II-III (1974-75), p. 317, quan diu, referint-se al tractat amb Granada signat per Martí l'Humà el 1405, que, en línies generals, les seves clàusules eren semblants a les que integrarien l'acord signat l'any següent entre Castella i l'estat nassarita. Per al tractat de Martí, vegeu P. de BOFARULL, CODOIN, vol. I, pp. 25-34; A. GIMÉNEZ, La Corona de Aragón, "BRABLB" IV (1907-1908), pp. 358-361, i M. MASALA, Martino l'Umano: trattato di pace con Granada (1405), dins Sardegna, Mediterraneo e Atlantico tra Medioevo ed Età Moderna. Studi storici in memoria di Alberto Boscolo, Roma, Bulzoni Editore-Deputazione di Storia Patria per la Sardegna, 1993, vol. II, pp. 327-341; pel que fa a les negociacions, vegeu A. GimÉnEz, La Corona de Aragón. "BRABLB" IV (19071908), pp. 351-352; M.T. FERRER, La frontera, pp. 179 i següents, i també M.D. LóPEZ, La Corona de Aragón..., pp. 190-193. Pel que fa a les relacions comercials entre Castella i Granada en períodes de pau i quan les treves estipulaven l'obertura de ports, remeto, essencialment, a J. RODRÍGUEZ MOLINA, Relaciones pacíficas en la frontera de Granada con los reinos de Córdoba y Jaén, dins La Península Ibérica, vol. II, pp. 1333-1372, i a IDEM, Relaciones pacíficas en la frontera con el Reino de Granada, dins La frontera, pp. 257-290, a les consideracions i bibliografia allí ressenyades.
} 
dubitativa, puix que, ell mateix, posava en qüestió la licitud del comerç amb els sarraïns. Els arguments de Mercader (que assegurava haver-ne parlat i tenir l'aprovació, fins i tot, de fra Vicent Ferrer) per intentar convèncer el monarca donen mostra d'una mentalitat ben diversa: al capdavall, els intercanvis amb els musulmans, fossin del caràcter que fossin els productes que els conformessin, sempre eren beneficiosos, ja que abastien les terres cristianes de l'or que era necessari per combatre'ls militarment ${ }^{28}$.

\section{LA RECUPERACIÓ DE LA TRADICIÓ CATALANOARAGONESA: LA INFLUÈNCIA DE JOAN MERCADER EN L'ELABORACIÓ DE LA TREVA}

La primera notícia que tenim de la negociació de la treva, del febrer de 1418, ens permet corroborar, amb pràctica seguretat, que Yusuf III i Alfons el Magnànim no havien iniciat, amb anterioritat, cap mena de contacte destinat a negociar un tractat de pau. Fou Muhammad VIII el Petit de Granada, que havia substituït el seu pare a la primeria de novembre de 1417, qui portà la iniciativa i envià una carta al monarca catalanoaragonès per proposar-li que, seguint el camí de l'amistat de llurs respectius progenitors, acceptés de negociar amb ell un tractat de pau i per notificar-li que, amb aquesta finalitat, li enviava, com a missatger, l'alcaid granadí Hayrin ${ }^{29}$.

Després d'aquesta carta del granadí, cal esperar fins a mitjan mes d'abril de 1418 per trobar els primers indicis que Alfons el Magnànim havia acceptat entaular les negociacions, que el resultat de la primera entrevista fou molt profitós i que els tractes quedaren ben embastats. La carta que, el 17 d'abril, Alfons el Magnànim escriví a Muhammad VIII indica que el missatger nassarita ja estava a punt d'iniciar el camí de retorn cap a les seves terres i que Alfons havia encarregat al batlle general del regne de València,

\footnotetext{
${ }^{28}$ Vegeu-ho a R. SALICRÚ, Relacions, vol. I, pp. 701-718; M. Tintó, Cartas del baile general de Valencia, Joan Mercader, al rey Fernando de Antequera, València, Instituto Valenciano de Estudios Históricos-Institución Alfonso el Magnánimo, Diputación Provincial de Valencia, CSIC, 1979, ja donava a conèixer i editava algunes d'aquestes cartes.

${ }^{29} \mathrm{~L}$ 'original d'aquesta carta, expedida en castellà per la cancelleria nassarita, en paper rosat i degudament autentificada, s'ha conservat, encara que molt malmès, a ACA, C., Cartes Àrabs, caixa 6 , núm. 180
} 
Joan Mercader, que s'ocupés dels afers relacionats amb l'ambaixada i amb la redacció de la treva ${ }^{30}$.

I, certament, si el monarca catalanoaragonès comissionà al batlle de València tot allò que feia referència a la concòrdia, els comptes de l'administració de la batllia posen de manifest que Mercader se n'ocupà a consciència i amb celeritat, puix que es féu fer trasllats i registrar als llibres del seu ofici diversos documents relacionats amb pactes anteriors amb el regne de Granada: a la primeria d'abril, pagà 12 sous al notari de València Gabriel Vives per haver-li registrat "II paus ab alcuns altres actes et enantaments que lo senyor rey don Martí, de loable memòria, féu ab lo rey de Granada"31; a la fi de maig, s'havia fet "scriure et registrar en los libres de mon offiçi les paus e treves fermades per los senyors reys d'Aragó, de gloriosa memòria, ab los reys de Granada" ${ }^{32}$; i, finalment, encara es féu fer trasllat "de una pau del rey de Granada fermada ab lo senyor rey en Pere", pau que, juntament amb la còpia de la venda "feta per lo senyor rey en Martí a çerts hòmens de Barcelona de les viles de Elg e de Crivillén", ocupà "XV fulles de letra spessa"33. Ignorem de quina de les diverses paus signades per Pere el Cerimoniós amb Granada durant el seu llarg regnat devia tractar-se $\mathrm{e}^{34}$, i també resulta una incògnita per quin motiu es mencionen dues paus del rei Martí, perquè, que se sàpiga, Martí l'Humà només arribà a concloure l'acord de $1405^{35}$.

${ }^{30}$ ACA, C., reg. 2664, f. 107v. 1418, abril, 17. València. El 20 d'abril l'alcaid Hayrin ja rebé d'Alfons un salconduït, de tres mesos, per tornar cap a Granada (ACA, C., reg. 2563, f. 146r-v. 1418, abril, 20. València). El llibre de comptes del Mestre Racional del regne de València, que permet precisar diverses dades relacionades amb l'arribada, estada i partença de València, on hi havia el rei, de l'ambaixador nassarita, confirma que la iniciativa fou granadina, ja que assegura que havia estat tramès al senyor rey per la treva que lo dit rey de Granada volia ab lo dit senyor (ARV, MR, Comptes d'Administració, reg. 38 (1418), ff. 130v, 132v, 139r i 166v).

${ }^{31}$ Íbidem, f. 158r.

${ }^{32}$ Per aquests trasllats i els de diversos capitols fets per lo senyor rey en Pere en les corts de Monçó per les cenes de absència, pagà 18 sous més al mateix notari, Gabriel Vives; ibidem, f. $160 \mathrm{v}$

${ }^{33}$ Ibidem; el trasllat de la pau i de la venda d'Elx i Crevillent a Barcelona costà 15 sous

${ }^{34}$ Vegeu M.T. Ferrer, La frontera, pp. 139-170, i A. GimÉnEz, La Corona de Aragón..., "BRABLB" IV (1907-1908), pp. 200-225, 271-298 i 342-349.

${ }^{35}$ Vegeu M.T. FERRER, La frontera, pp. 178-186. De tota manera, quan Martí morí hi havia gairebé enllestida una nova concòrdia i, en conseqüència, la segona de les II paus podria ser-ne l'esborrany. 
Per tant, si Alfons el Magnànim va encarregar la gestió de la negociació del tractat a Joan Mercader, aquest va prendre's ben seriosament la comesa i revisar a fons els acords signats pels monarques catalanoaragonesos anteriors a Alfons, remuntant-se, com a mínim, fins a Pere el Cerimoniós, cosa que, com veurem tot seguit, queda ben palesa amb l'anàlisi del contingut del text del tractat que ens ha pervingut.

Lluny del que havien estat els pactes de Ferran I, redactats seguint el model dels tractats castellans i les clàusules dels quals reproduïen fidelment, al peu de la lletra, les que ja havien conformat la treva castellanogranadina de $1410^{36}$, la intervenció de Mercader (personatge a qui el Magnànim reservà una gran influència en les seves relacions amb Granada, almenys mentre estigué al capdavant de la batllia general del regne de València ${ }^{37}$ ) en l'elaboració de la treva - però també en la seva negociació $^{38}$ i posterior fracàs- fou cabdal per determinar-ne el contingut, perquè la voluntat de recuperar la tradició catalanoaragonesa fou, per davant de tot, seva.

Perquè, com he dit més amunt, fou ell, com a batlle general del regne de València, qui es féu ressò de les actituds, voluntats i protestes de la classe mercantil valenciana i qui canalitzà l'oposició indirecta a les condicions dels tractats subscrits per Ferran d'Antequera que, arran de les diferències derivades d'una concepció diversa de les relacions i del comerç amb "terra de moros", potenciaren l'aparició d'un virulent focus de pirateria castellana a Cartagena. Però també perquè havia estat igualment ell, com a portantveus dels mateixos mercaders valencians, qui s'oposà amb més rotunditat a l'anomenat "contracte de la seda" o monopoli d'importació de la seda granadina que havien aconseguit, el 1417, mitja dotzena de mercaders valencians, que provocà la reacció dels altres mercaders del regne que comerciaven el sultanat, que se'n consideraven perjudicats, i que, encara

\footnotetext{
${ }^{36}$ Cf. J. de M. CARriazo, Un alcalde, pp. 65-70 i Crónica Juan II..., pp. 402-408.

${ }^{37}$ Remeto, en aquest sentit, a R. SALICRÚ I LLUCH, Joan Mercader: la intervenció del batlle general del regne de València en la política granadina d'Alfons el Magnànim. "Anales de la Universidad de Alicante" 12, en curs de publicació.

${ }^{38} \mathrm{No}$ ens pertoca, aquí, analitzar a fons el desenvolupament de les negociacions, que Mercader dirigí i supervisà, personalment, fins al més mínim detall, i que, a Granada, foren fins i tot conduïdes, directament, per un seu fill i futur batlle general del regne de València, Berenguer Mercader, per a la qual cosa remeto, més per extens, a R. SALICRÚ, El sultanat..., pp. 145-155 ("Negociacions i signatura de la treva de 1418").
} 
que fos indirectament, seria un dels elements claus per determinar el posterior fracàs de l'acord ${ }^{39}$.

\section{L'ACORD DE 1418 , PUNT DE CONFLUÈNCIA DELS TRACTATS ANTERIORS}

L'anàlisi del contingut de la treva de 1418 palesa, sense complexes, que aquesta tenia com a referent immediat la treva de Martí l'Humà de 1405, la darrera que la Corona d'Aragó havia signat amb Granada abans del "parèntesi castellà" de les treves ferranianes, ja que diversos capítols remeten a l'estat de les coses d'aquell moment ${ }^{40}$.

Si bé la durada del pacte del rei Martí fou de cinc anys (que solia ser, almenys des de la primeria del segle XIV, el període habitual de vigència de les treves catalanoaragoneses amb Granadal ${ }^{41}$ i la del del Magnànim era de $\operatorname{dos}^{42}$, la majoria de clàusules de tots dos tractats són molt similars. En varia, això sí, l'ordre d'enumeració i, sovint, els detalls

\footnotetext{
${ }^{39}$ Remeto, en aquest sentit, a R. SALICRÚ, El sultanat, pp. 136-141 ("El contracte de la seda: cap al fracàs de la futura treva de 1418") i pp. 155-164 ("El fracàs de la treva i la treva castellanogranadina de 1419").

${ }^{40}$ Ja he dit que la treva és publicada per P. de BOFARULL, CODOIN, vol. I, pp. 25-34; A. Giménez, La Corona de Aragón, "BRABLB" IV (1907-1908), pp. 358-361; i M. MASALA, Martino l'Umano, pp. 327-331. La citaré, en endavant, per simplificar, segons l'edició de Giménez Soler.

${ }^{4}$ Foren negociades per cinc anys, per exemple, les treves de 1305 (cf. A. GIMÉNEZ, La Corona de Aragón, "BRABLB" IV (1907-1908), pp. 150-151), 1326 (cf. A. MASIÀ I DE ROS, Jaume II: Aragó, Granada i Marroc, Barcelona, CSIC, 1989, pp. 550-554), 1357 -acordada també amb el Marroc- (cf. A. Giménez, La Corona de Aragón. "BRABLB" IV (1907-1908) pp. 279-281), 1369 (cf. ibidem, pp. 297-298), 1377 (cf. ibidem. pp. 342-344), 1382 (cf. M.T. FERRER, La frontera, pp. 164-165. i Ch.-E. DUFOURCQ, Catalogue chronologique et analytique du registre 1389 de la chancellerie de la Couronne d'Aragon, intitulé "Guerre Sarracenorum 1367-1387 (1360-1386)". "MTM" 2 (1974), pp. 140-141, doc. 267), 1392 (cf. M.T. FERRER, La frontera, pp. 174-175) i 1405 (cf. P. de BOFARULl, CODOIN, vol. I, pp. 25-34; A. Giménez, La Corona de Aragón, "BRABLB" IV (1907-1908), pp. 358-361, i M. MaSALA, Martino l'Umano, pp. 327-331).

42Del 4 de juliol de 1418 fins al 4 de juliol de 1420 (remeto, d'ara en endavant, per a les referències al text de la treva, a ACA, C., reg. 2641, ff. 153v-156r. 1418, juliol, 4. Saragossa, ed. R. Salicrú, Relacions, vol. II, doc. 45). Alfons el Magnànim delegà tan plenament la negociació en Joan Mercader i confià en ell i en la seva gestió fïns a tal punt que, tot $\mathrm{i}$ que el batlle féu el gest de deixar en blanc la durada del tractat, l'única cosa que Alfons hagué de fer escriure en el text final, es permeté aconsellar-li que fos com a màxim de dos anys i, si no, com a mínim d'un (ACA, C., CR Alfons IV, caixa 7, núm. 867. 1418, juny, 17. València, ed. R. SAliCrú, Relacions, vol. II, doc. 44).
} 
i la precisió de la redacció, de vegades en favor de l'un i de vegades en favor de l'altre.

Tanmateix, cal dir que la majoria de discrepàncies entre el tractat de $1405 \mathrm{i}$ el de 1418 tenen la seva arrel i troben paral-lelisme en altres tractats previs, cosa que demostra fins a quin punt el batlle general del regne de València va fer a consciència la tasca que li havia comissionat Alfons el Magnànim: és evident que, abans de procedir a la redacció del text del tractat de 1418, Joan Mercader va estudiar i analitzar en profunditat els acords anteriors, d'alguns dels quals, segons hem vist, se n'havia fet fer trasllat; i és evident, també, que, tot i que prengués com a base la treva del rei Martí del 1405, el precedent més immediat, no es va conformar amb una simple còpia o actualització de les seves clàusules, sinó que la completà, espigolant, a consciència, aquells punts dels pactes anteriors que li semblà que podien millorar-la.

El que no recullen, però, ni el tractat de 1405 ni el de 1418 i que, en canvi, era present en tractats anteriors, és el reconeixement del dret dels sarraïns catalanoaragonesos de marxar lliurement a països musulmans.

Des del segle XII, els reis d'Aragó i els comtes de Barcelona s'havien compromès a respectar la religió, usos, costums i llibertat d'emigració dels nous súbdits musulmans que romangueren a les terres que els cristians havien anat conquerint. Tot i que, des de bon començament, el dret d'emigració era subjecte a la petició d'una llicència, durant la primera meitat del segle XIV aquest dret fou respectat. Però, més o menys a mitjan segle XIV, l'actitud de la Corona començà a canviar i a fer-se més restrictiva, segurament a causa de les pressions de la noblesa, la principal perjudicada per la despoblació que l'emigració comportava, agreujada després de la Pesta Negra i de la guerra amb Castella. Per això, la Corona rebé pressions de caràcter oposat tant de la noblesa valenciana com de les autoritats nassarites, que sovint quedaren reflectides a les clàusules de les treves ${ }^{43}$. Durant el regnat de Martí l'Humà, els nobles acabaren per aconseguir llur propòsit, i l'emigració dels sarraïns fou prohibida, a les Corts de València, el 1403. En les negociacions per a la signatura del tractat de pau de 1405, Granada insistí per a incloure-hi una clàusula assegurant la

\footnotetext{
${ }^{43}$ Malgrat la resistència oposada uns anys abans a aquesta clàusula, el 1377 Pere el Cerimoniós encara es comprometé a no prohibir l'emigració dels sarräns dels seus regnes $(c f$. M.T. FERRER, La frontera, p. 164); però, en canvi, la clàusula no fou inclosa a la treva de 1382 (ibídem, p. 165)
} 
llibertat d'emigració dels moros residents a la Corona catalanoaragonesa, però com que el rei Martí no estava disposat a cedir si no es podia conjuminar amb el capítol concedit a les corts, l'acord fou signat, finalment, sense el capítol objecte de discussión ${ }^{44}$. El 1418, el rei Alfons seguia penalitzant qualsevol temptativa d'emigració dels sarraïns valencians, abocats, aleshores, a les fugides clandestines $i$, malgrat les vacil-lacions del monarca, aquest fou un dels principals problemes als que el batlle general del regne de València hagué de fer front al llarg del seu regnat ${ }^{45}$.

No és pas estrany, per tant, que ni la treva de 1405 ni la de 1418 no fessin referència a la llibertat d'emigració dels sarraïns cap a Granada i altres terres musulmanes.

El que resulta sorprenent és, en tot cas, que, al costat dels capítols de l'acord de 1418 que, segons Berenguer Mercader - l'ambaixador que anà a Granada amb la intenció d'assistir a la ratificació del tractat per part de Muhammad VIII però que, al capdavall, només fou testimoni del seu fracàs-, els granadins més qüestionaven (la durada de la pau i les clàusules sobre l'ajut de cavallers i galeres, sobre corsaris, sobre almogàvers i sobre les innovacions fiscals ${ }^{46}$ ), no es fes menció de la llibertat de sortida dels

\footnotetext{
${ }^{44}$ Vegeu M.T. FERRER I MALLOL, Els sarraïns de la corona catalano-aragonesa en el segle XIV. Segregació i discriminació, Barcelona. Institució Milà i Fontanals - CSIC, 1987, pp. 147183 ("L'emigració a països sarraïns"). Vegeu també IDEM, L'emigració dels sarraïns residents a Catalunyar, a Aragó i al País Valencià durant la baixa edat mitjana, dins L'expulsió dels moriscos: conseqüencies en el món islàmic i el món cristià: Sant Carles de la Ràpita, 5-9 desembre 1990: 380è. aniversari de l'expulsió dels moriscos. Congrés internacional. Barcelona. Departament de Cultura de la Generalitat de Catalunya, 1994, pp. 19-26.

${ }^{45}$ Vegeu M.T. Ferrer, L'emigració, pp. 23-26; A. Díaz Borrás, La paradoja de la emigración mora en Valencia durante el siglo XV. Expatriación musulmana en época de Honorat Mercader (1467-1481). "Cuadernos de Estudios Medievales y Ciencias y Técnicas Historiográficas" 16 (1991), pp. 37-58; L. PILES ROS, La situación social de los moros de realengo en la Valencia del siglo XV, "Estudios de Historia Social de España" I (1949), pp. 225-274; IDEM, Estudio documental sobre el bayle general de Valencia, su autoridad y jurisdicción. València, Institución Alfonso el Magnánimo-CSIC, 1970, i M.L. ORTELLS, Los mudéjares de Valencia en el siglo XV a través de los "Delmaments dels sarrahins". dins Actas del V Simposio Internacional de Mudejarismo (1990). Terol, Instituto de Estudios Turolenses, 1991, pp. 135-145. Per a un moment més tardà, E. SALVADOR, Sobre la emigración mudéjar a Berbería. El tránsito legal a través del puerto de Valencia durante el primer cuarto del siglo XVI, "Estudis" 4 (1975), pp. 39-68, i per al segle XIV, M.T. FERRER, Els sarraïns, pp. 105210.

${ }^{46}$ Així consta a A. GiménEz, La Corona de Aragón, "BRABLB" IV (1907-1908), pp. 370372. [1418], setembre, 4. Alcalà de Bençayt lla Real], en la transcripció d'una carta que, actualment, ja no he pogut localitzar entre els fons de l'Arxiu de la Corona d'Aragó; remeto de nou, més per extens, a R. SALICRÚ, El sultanat, pp. 155-164, "El fracàs de la treva i la treva castellanogranadina de 1419".
} 
sarraïns valencians. Perquè, malgrat tot, les autoritats nassarites no havien pas renunciat a defensar i proclamar aquest dret dels seus coreligionaris, tal com pot demostrar-se, almenys en una ocasió, durant el regnat de Yusuf III, quan el seu missatger Ali Barramoni, en ser a Barcelona, a la fi de 1409 o a l'inici de 1410, per anar a trobar el rei Martí i negociar-hi la renovació del tractat de 1405, llançà des d'allí una proclama, en nom del sultà, que instigava els sarraïns catalanoaragonesos a emigrar cap a Granada ${ }^{47}$.

La part introductòria del text de l'acord de 1418, igual que la del del rei Martí de 1405, deixa molt clar que havia estat el rei de Granada qui desitjava tenir pau, tal com ho havia comunicat de part seva a Alfons el Magnànim "Hayren, fillo de Hayretla, cavallero, misatgero e procurador vuestro nuevament a nós enviado", i que, com que el rei Alfons s'havia mostrat d'acord a concedir la concòrdia, ell i el missatger granadí, com a procurador de Muhammad i en nom seu, l'havien conclosa.

\footnotetext{
${ }^{47}$ És probable que, en la negociació de la pròrroga del tractat, Yusuf III volgués tornar a intentar d'incorporar la clàusula relativa a la llibertat d'emigració dels sarraïns $i$ que, davant de la nova negativa de Martí, l'ambaixador es decidís a emetre les consignes que instigaven els sarraïns a fugir, a emigrar, clandestinament, cap a Granada. El document fou regestat i publicat, primer, en àrab, per J. RiBera, M. Asín, Manuscritos árabes y aljamiados de la Biblioteca de la Junta, Madrid, Centro de Estudios Históricos, 1912, pp. 258-260, i posteriorment, per W. HOENERBACH, Spanish Islamische Urkunden aus der Zeit der Nasriden und moriscos, University of California Press, Berkeley and los Angeles / Selbstverlag des Orientalischen Seminars der Universität Bonn, 1965, que en donà traducció i comentari a W. HoEnERBACH, Cuatro documentos mudéjares originarios de Cataluña y de Levante, dins Homenaje al Profesor Darío Cabanelas Rodríguez, O.F.M. con motivo de su LXX aniversario, vol. I, Granada, Universidad de Granada. 1987. pp. 369-372. Tant C. BARCELó, Minorias islámicas en el País Valenciano. Historia y dialecto, València, Universitat - Instituto Hispano-Árabe de Cultura, 1984, p. 40 , com M. RuZAFA GARCía, Els origens d'una familia de mercaders mudèjars en el segle XV: Caat Ripoll (1381-1422), "Afers" 7 (1988-89). p. 181, que segueix aquesta autora, ho consideren, recollint el testimoni de Ribera. una proclama política que anima les aljames mudèjars a ajudar Yusuf III en la guerra contra els cristians, però la traducció de Hoenerbach evidencia que el que fa és. només, incentivar lemigració dels musulmans cap a terres islàmiques perquè no hagin de viure sota domini dels infidels, cosa que era considerada un deure per tot musulmà i que. després de les mesures restrictives aprovades pel rei Martí el 1403 i la impossibilitat que el tractat de 1405 garantís aquest dret dels coreligionaris, esdevé del tot comprensible. Sobre el deure d'emigració dels sarraïns, encara que sigui fent referència al moment immediat a la conquesta de Granada i a l'emigració cap al Magrib, vegeu F. MaílLo Salgado, Consideraciones acerca de una fatw'a de al-Wansarisi, "Studia Historica" III/2 (1985), pp. 417-423, i J.E. LÓPEZ DE COCA CASTAÑER, Granada y el Magreb: la emigración andalusí (1485-1516), dins Relaciones de la Península Ibérica con el Magreb, Madrid, CSICInstituto Hispano-Árabe de Cultura, 1988, pp. 417-423.
} 
En primer lloc, després de fer constar que la pau seria vàlida per dos anys des del dia que el rei de Granada l'hagués ratificada ${ }^{48}$, el pacte feia referència a la llibertat de moviment dels súbdits d'Alfons i de Yusuf a totes les ciutats, viles, llocs i terres respectives, amb tots els béns i mercaderies que volguessin ${ }^{49}$. I, si es donava el cas que el propietari d'uns béns o el seu factor morien durant la pau, la persona que hi anés amb carta del rei del qual el mort fos vassall per emportar-se'n aquests béns havia de poder fer-ho sense cap problema ${ }^{50}$.

Per altra banda, feia constar que tant granadins com catalanoaragonesos quedaven eximits del pagament de qualssevol drets introduïts després de la pau de $1405^{51}$.

Aquesta exempció fiscal que, al text de la treva, sembla tan matisada i que, gairebé, passa desapercebuda, ha de ser la del "dret de la seda que es estat imposat novament als mercades" catalanoaragonesos, una de les clàusules que els nassarites volien anul·lar de l'acord però que Berenguer Mercader deia que era completament innegociable i que, de cap manera, no pensava consultar al monarca, perquè sabia que no hi transigiria per res de res.

\footnotetext{
${ }^{48} \mathrm{La}$ durada de la pau fou. com ja he dit, un dels principals esculls que impediren que els nassarites ratifiquessin l'acord, puix que, segons la carta de Berenguer Mercader a la qual he fet esment abans, volien que ell consultés Alfons "especialment de la pau que fos a IIII anys, car lo rey de Granada no fermaria en altra manera la pau".

${ }^{49} \mathrm{El}$ text de 1405 , com el de molts altres tractats, precisa que podien comerciar per terra, per mar i per aigua dolça, i concreta que podien treure'n or i tota mena de mercaderies $(c f$. A Giménez. La Corona de Aragón, "BRABLB" IV (1907-1908), p. 358). A diferència de les treves castellanogranadines, des de mitjan segle XIV les catalanoaragoneses no feien explícita la prohibició de comerciar amb coses vedades, és a dir, vitualles, ferro, fusta, armes i altres mercaderies de caràcter estratègic o susceptibles de ser aprofitades, com a material bèl-lic, contra els cristians per part de 1 '"enemic" musulmà (la prohibició figura, només, de manera explícita, als tractats de 1305,1326 i 1344). Almenys des del darrer quart del segle XII, al III Concili del Laterà de 1179, i al llarg de tota l'Edat Mitjana, amb successives atenuacions i vigoritzacions, el papat havia prohibit. amb petites variacions conjunturals, el comerç d'aquests productes amb els estats de religió islàmica; vegeu J. TRENCHS ODENA, "De alexandrinis" (El comercio prohibido con los musulmanes y el papado de Aviñón durante la primera mitad del siglo XIV). "AEM" 10 (1980), 237-320.

${ }^{50}$ Aquest punt no apareix a la treva de 1405, ni tampoc no he sabut localitzar-lo en cap dels tractats anteriors. La seva inclusió a l'acord de 1418 podria ser fruit, potser, dels problemes que sabem que alguns mercaders havien tingut, durant el regnat de Ferran d'Antequera, per recuperar els béns que els seus factors, difunts, tenien al regne de Fes, problemes que he recollit a R. SALICRÚ, Relacions, vol. I. pp. 201-224.

${ }^{51} \mathrm{~A}$ la treva de 1405 no s"hi inclou cap referència fiscal. tot i que altres tractats especifiquen, únicament i genèrica. que s`havien de satisfer els drets habituals.
} 
El dret de la seda que Granada havia imposat feia poc i amb posterioritat a la treva de 1405 als mercaders catalanoaragonesos té el seu fonament, sense cap mena de dubte, en el ja esmentat contracte o monopoli de la seda que diversos mercaders cristians de la ciutat de València havien signat amb Yusuf III el 1417 i que, per una carta que Joan Mercader va adreçar a Alfons el Magnànim el 22 de febrer de 1417, sabem que augmentaven "lo dret del dit rey de Granada, qui és acostumat ésser deu per çentenar, que sia quinze per çentenar". Com que, segons el batlle, la seda era la base de les importacions valencianes del regne nassarita i "no[-s po]t exir esmerç gros de Granada sens la seda", gaudir del monopoli de la seda també suposava, segons ell, indirectament, gaudir del monopoli de les importacions i exportacions de Granada, almenys de les valencianes, de manera que, "per aquesta indirectitud, lo rey de Granada collirà lo dit dret de quinze per çentenar no solament de la seda de son regne, ans encara de tots los avers d'aquest regne [de València] qui sien per a anar lla [a Granada]" ${ }^{15}$.

Com ja he dit, Mercader fou qui canalitzà, sense èxit, l'oposició de la resta de mercaders valencians a aquest monopoli, perquè el "contracte" acabà signant-se, tal com testimonia no només Berenguer Mercader sinó també la documentació municipal valenciana ${ }^{53}$ i, per tant, Muhammad VIII

${ }^{52}$ ACA, C., CR Alfons IV, caixa 4, núm. 410. 1417, febrer, 22. València, ed. B. GaRí, R. SALICRÚ, Las ciudades del triángulo: Granada, Málaga, Almería ye el comercio mediterráneo de la Edad Media, en D. ABUlafia - B. GaRí (dir.), En las costas del Mediterráneo Occidental: Las ciudades de la Península Ibérica y del reino de Mallorca y el comercio mediterráneo en la Edad Media, Editorial Omega, Barcelona, 1996, doc. 2, i R. SAlicrú, Relacions. vol. II, doc. 20. De fet, R. ARIÉ, L'Espagne musulmane au temps des Nasrides: 1232-1492. Réimpression suivie d'une postface et d'une mise à jour par l'auteur. París, de Boccard, 1990, p. 362, nota 3 (basant-se en S. CARRERES ZACARÉS, Valencia y Alfonso el Magnánimo. "Anales del Centro de Cultura Valenciana" XIV (1946), pp. 194-195), ja havia fet referència a aquest monopoli a partir de la documentació municipal valenciana. però havia interpretat, confonent-se a causa de la poca claredat del text de Carreres, que el monarca musulmà anul-là el contracte. Sobre aquest "contracte de la seda", vegeu R. SALICRú, El sultanat, pp. 136-141.

${ }^{53} \mathrm{El}$ juliol de 1417 els paraires de València feien referència, també, a lo contracte de la seda que alguns mercaders de aquesta ciutat han fermat ab lo rey de Granada, que consideraven molt dampnós als dits perayres e comú de la dita ciutat, i intentaren aconseguir, amb el suport de Joan Mercader, que fos revocat; $c f$. Arxiu Municipal de València, Manuals de Consell, A-26, ff. $269 \mathrm{v}$ i 290r, dades que he obtingut a través de G. NAVARRO ESPINACH, El despegue de la industria sedera en la Valencia del siglo XV. València, Generalitat de València-Consell Valencià de Cultura, 1992, p. 40 i nota 46. que cita R. NARBONA, Gobierno político y luchas sociales. Estrategias de poder del patriciado urbano. La ciudad de Valencia (1356-1419), tesi doctoral inèdita. València, Universitat, 1989, p. 812 i nota 121, obra que jo no he consultat. Hom, tanmateix, ja hi havia fet referència reiterada (vegeu, per exemple, IDEM, Valencia, municipio 
devia haver heretat del seu pare aquesta innovació fiscal, introduïda, en conseqüència, el 1417. I com que Joan Mercader havia estat qui s'havia mostrat més bel-ligerant amb la signatura del contracte de la seda i, a la vegada, havia estat el veritable artífex de la treva de 1418, no és estrany que, per mitjà d'aquesta, hagués intentat de nou neutralitzar aquelles repercussions fiscals; i més, tractant-se d'una qüestió tan recent i que perjudicava, essencialment, els mercaders del regne del que ell era batlle. Això també explicaria que, en el text de la treva, la voluntat d'anul·lació d'aquest dret passi desapercebuda, sota una clàusula general que preveu que "los ditos vassallos de cada uno de nós, ditos reyes, no sean tenidos pagar dreytos algunos que sean puestos aprés del tiempo de la paz que fue contractada entre los reyes don Martín (...) e don Mahomat (...), más que sean tenidos pagar los dreytos antigos acostumbrados", i que no s'hi esmenti directament el dret de la seda, perquè, en el fons, aquesta clàusula no seria més que el reflex de la particular concepció que Joan Mercader tenia del dret de la seda, com a imposició que afectava globalment, encara que de manera indirecta, tot el comerç amb Granada. En contrapartida, aquest fet també permetria entendre perquè, en canvi, a diferència del text de la treva, la carta de Berenguer Mercader polaritzava la pugna fiscal en el dret de la seda: en aquest punt, la carta de l'ambaixador parlava per boca dels nassarites, que sabien perfectament què amagava en realitat aquest capítol abstracte.

En la següent clàusula de la treva de 1418, Muhammad VIII es comprometia a no ajudar cap rei, comte $^{54} \mathrm{ni}$ amic d'Alfons que s'alcés contra ell, ni per mar ni per terra, ni tampoc amb cavallers, peons, cavalls

medieval. Poder político y luchas ciudadanas. 1239-1418, València, Ajuntament de València, 1995, p. 156 i nota 75; G. NAVARRO ESPINACH, La seda entre Génol'a, Valencia y Granada en época de los Reyes Católicos, dins La frontera... pp. 478-479; P. IRADIEL MURUGARREN, G. Navarro Espinach, La seda en Valencia en la Edad Media, dins España y Portugal en las rutas de la seda. Diez siglos de producción y comercio entre Oriente y Occidente, Barcelona, Universitat, 1996, p. 186, o M. RUZAFA GARCíA, Los operadores económicos de la morería de Valencia, dins Actas. IV Simposio Internacional de Mudejarismo: Economía. Teruel, 17-19 septiembre de 1987, Teruel, Instituto de Estudios Turolenses, 1992, p. 252).

${ }^{54}$ Referència implícita, tal vegada, a l’"experiència" de Jaume d'Urgell durant l'Interregne, pels contactes que havia tingut amb Yusuf III contraris a Ferran d'Antequera? Per a aquests contactes, vegeu, de nou, R. SALICRÚ. El sultanat, pp. 48-63 ("Els suposats contactes entre Jaume d'Urgell i Yusuf III de Granada"). 
o armes ni de cap altra manera. En justa correspondència, Alfons tampoc no podria ajudar cap enemic de Muhammad ${ }^{55}$.

Durant els dos anys de la pau, tota fusta de súbdits de l'un o de l'altre, encara que fos de corsaris, que arribés a qualsevol punt de la costa, platja o port de qualsevol vila, lloc o terra de l'altre, podria estar-hi segurament, podria vendre qualssevol mercaderies o béns que portés i podria avituallar-se d'aigua o de qualsevol altra cosa que necessités, i llurs vassalls respectius els haurien d'ajudar, emparar i defensar, amb tot llur poder, de llurs enemics ${ }^{56}$.

Segons la carta de Berenguer Mercader, aquest capitol dels cossaris era un dels que els granadins feien fita, però que ell va acabar acceptant, finalment, abans de la ruptura definitiva de les negociacions, de consultar a Alfons per si accedia a modificar-lo.

Igualment, tots els tripulants, embarcacions i tot el que portessin qualssevol fustes que, per naufragi o per persecució d'enemics, arribessin a qualsevol port, platja o maresme de ciutats, viles o llocs de l'altre, també quedarien sota guarda i seguretat, i se'n podrien descarregar tots els béns i mercaderies sense pagar cap dret. Els mariners podrien comprar tot allò que necessitessin per reparar la nau (antenes, arbres, governs, veles o qualsevol altra cosa necessària) i, si convenia, una altra fusta, i no se'ls exigiria un preu excessiu ${ }^{57}$. Hom els hauria d'ajudar a vendre i a recuperar el preu de tot allò que volguessin vendre. I no estarien obligats, per cap d'aquestes coses, a pagar, per aquest motiu, cap dret, ni tampoc cap dels imposats

\footnotetext{
${ }^{55} \mathrm{La}$ treva de 1405 no és tan explícita: només diu que durant la pau ni Martí, ni Muhammad VII, ni llurs vassalls, no podrien prestar ajut contra l'altre a cap rei o príncep (cf. A. GIMÉNEZ, La Corona de Aragón.... "BRABLB" IV (1907-1908), p. 359). La clàsula és present a tots els tractats catalanoaragonesos amb Granada, que especifiquen, conjunturalment, la prohibició d'ajudar el rei de Castella.

${ }^{56}$ El tractat de 1405 incorpora una clàusula equivalent ( $c$. A. GIMÉnEZ, La Corona de Aragón, "BRABLB" IV (1907-1908). p. 359) que també apareix en diversos tractats anteriors, com el de 1382. En canvi, el 1386, segons el memorial que el Cerimoniós va lliurar a Bernat Senesterra perquè negociés la renovació de la treva de 1382. el rei Pere volia suprimir de la clàusula de bon acolliment de vaixells als ports de tots dos estats la referència als vaixells corsaris, perquè volia que fossin considerats presa legítima ( $c f$. M.T. FERRER, La fromtera, $\mathrm{p}$. 169, i Ch.-E. DufourCQ, Catalogue, p. 150, doc. 304). Al tractat de 1392, la clàusula ja tornava a estipular que les embarcacions corsàries havien de ser ben acollides als ports de l'aliat (cf. M.T. FERRER, La frontera, p. 174).

${ }^{57}$ Clàusula equivalent al tractat de 1405 ( $c$. A. GimÉnEz, La Corona de Aragón... "BRABLB" IV (1907-1908), p. 359), però que no reconeix el dret de comprar una altra fusta En canvi, aquest dret era reconegut als tractats de 1367 i de 1377 de Pere el Cerimoniós (cf. ibídem, pp. 292 i 343).
} 
després de la pau signada entre els reis Martí l'Humà i Martí de Sicília i Muhammad VII -cosa que, indirectament, demostra que se n'havien introduï-; però, en canvi, s'especifica que s'haurien de pagar els dreytos antigos acostumbrados ${ }^{58}$.

Quan fustes de gent de l'un o de l'altre monarca haguessin arribat en algun port o platja per avituallar-se de pa o refrescamiento, no podrien fer cap mal a cap fusta que estigués en aquell port o platja durant el viatge d'avituallament. Si, en canvi, durant un viatge que no tingués aquesta finalitat, volien danyar o danyaven alguna fusta, els súbdits de l'altre podrien impedir-ho, i ni aquests danys ni les accions per impedir-ho es considerarien transgressió de la treva ${ }^{59}$.

$\mathrm{Si}$, en el temps de la pau, un o altre conquerien algun lloc d'algun enemic seu $\mathrm{i}$ hi havia súbdits de l'aliat, llurs persones $\mathrm{i}$ possessions quedarien lliures i segures, i podrien marxar on volguessin. Igualment, si alguna embarcació de vassalls d'algun dels dos monarques prenia una nau on hi hagués sotmesos de l'altre, llurs persones i béns també quedarien lliures i segures, i podrien anar on volguessin, excepte si anaven en fustes de rems. Les persones i béns trobats i presos en embarcacions de rems, podrien ser captivats i damnificats lícitament, sense lesió de la pau ${ }^{60}$.

Sempre que enemics de l'un o de l'altre tinguessin captius de l'aliat i volguessin vendre'ls en qualsevol lloc de les seves platges, ports o mars, els seus súbdits respectius no podrien comprar-los, ni tampoc llurs mercaderies ni béns ${ }^{61}$.

\footnotetext{
${ }^{58} \mathrm{El}$ tractat de 1405 només diu que per aquest motiu no haurien de pagar cap dret, no fa referència als "drets antics"; $c f$. A. GIMÉNEZ, La Corona de Aragón, "BRABLB" IV (19071908), p. 359

${ }^{59} \mathrm{El}$ tractat de 1405 vetava per complet que qualsevol fusta pogués damnificar cap embarcació en cap port, platja o maresme del regne de l'altre; $c f$. A. GIMÉNEZ, La Corona de Aragón, "BRABLB" IV (1907-1908), p. 359. En canvi, la clàusula apareix exactament igual que el 1418 al tractat de Pere el Cerimoniós de 1377; $c f$. ibídem, p. 343.

${ }^{60} \mathrm{El}$ tractat de 1405 agrupa en un mateix epígraf els vassalls de l'altre rei que es trobessin en algun lloc conquerit $\mathrm{i}$ els que viatgessin en fustes de rems que poguessin prendre; uns $\mathrm{i}$ altres havien de quedar assegurats i lliures; $c f$. A. GIMÉNEZ, La Corona de Aragón, "BRABLB" IV (1907-1908), pp. 359-360. La consideració de presa legítima d'aquells que viatgessin en fustes de rems constava, com a novetat que Pere el Cerimoniós volia introduir al tractat de 1386, al memorial d'ambaixada que lliurà a Bernat Senesterra ( $c f$. Ch.-E. DufourCQ, Catalogue, p. 150. doc. 304); no figurava, en canvi, als pactes anteriors.

${ }^{61}$ La clàusula apareix igual al tractat de 1405 (cf. A. GIMÉnEZ, La Corona de Aragón..., "BRABLB" IV (1907-1908), p. 359) i també és habitual en pactes anteriors.
} 
Si i cada vegada que Alfons necessités ajut de Muhammad contra algun enemic seu, el rei de Granada hauria d'ajudar-lo amb tants cavallers com Alfons volgués, fins a un màxim de 400 o 500, amb la condició que hauria de pagar una soldada de 17 dobles d'or a cada cavaller i de 40 dobles d'or a llur alcaid o capità per cada mes de servei, sempre i quan l'enemic del catalanoaragonès no fos amic de Muhammad i Muhammad no necessités els cavallers per motius de guerra o per qualsevol altra raó. En aquests dos supòsits, Muhammad no estaria obligat a prestar-li aquest ajut. En contrapartida, cada vegada que Muhammad necessités l'ajut d'Alfons contra qualsevol enemic seu, el Magnànim hauria d'ajudar-lo per mar amb quatre o cinc galeres, excepte si els enemics del nassarita eren amics del catalanoaragonès o si necessitava les galeres per guerra o per qualsevol altre motiu. En aquests dos casos, Alfons no hauria de prestar-li l'ajut. Se sobreentenia que a cada galera hi hauria 220 homes, 30 dels quals ballesters, i que Muhammad pagaria, per llur soldada i per cada galera, 900 dobles d'or per mes de servei $^{62}$.

Com ja he dit més amunt, aquest capítol sobre l'ajuda dels cavallers $e$ de les galeres era un altre dels que els granadins feien fita, però, en darrer

\footnotetext{
${ }^{62}$ Aquest capítol també apareix al tractat de 1405 , però se li atribueix molta més importància, perquè és el segon de l'acord, que s'insereix immediatament després del que, tant el 1405 com el 1418, és el primer, el de la llibertat de comerç. És significatiu, a més, que allí s'esmentin primer les obligacions del rei Martí i després les de Muhammad VII, mentre que, el 1418, es defineixen primer les de Muhammad VIII i després les d'Alfons el Magnànim. Els efectius que granadins i catalanoaragonesos havien d'aportar són els mateixos, i també les soldades, amb la sola excepció de la dels cavallers, que el 1405 són 7 dobles i el 1418 en són 17 , però no hi ha dubte que tant el 1405 (avalada per les diverses edicions de la pau de 1405 i també per la presència de la mateixa clàusula als tractats de 1377, 1382 i 1392) com el 1418 la transcripció de l'original és correcta. Si prenem en consideració que la resta de dades són iguals i que la diferència de 7 a 17 dobles és molt significativa, la similitud de la xifra podria induir a creure que, el 1418, l'escrivà podria haver-se equivocat en fer la còpia del document: on el document de 1418 diu 17, en lletres, s'hi havia deixat un espai en blanc, i la quantitat hi fou escrita amb posterioritat. Aquest fet podria ser indicatiu de la necessitat de consultar la xifra, bé amb la intenció de copiar-la dels tractats anteriors, i aleshores errar-la, bé, a consciència, per modificar-la. El 1405 també es precisava que les galeres havien de ser armades i eixarciades però, en canvi, no s'insistia tan clarament que si hom necessitava els contingents o les galeres per altres finalitats no estarien obligats a prestar l'ajut ( $c f$. A. GIMÉNEZ, La Corona de Aragón, "BRABLB" IV (1907-1908), pp. 358-359). L'ajut mutu, en els mateixos termes i nombre de cavallers, capitans, galeres, ballesters i soldades respectives, però amb 7 dobles per cavaller, $\mathrm{i}$ en el mateix ordre que el 1418 (és a dir, indicant primer les obligacions catalanoaragoneses $\mathrm{i}$, en segon terme, les nassarites), apareix per primer cop al tractat de Pere el Cerimoniós de 1377 (cf. A. GimÉNEZ, La Corona de Aragón, "BRABLB" IV (1907-1908), pp. 343-344, i M.T. FERRER, La frontera, 164) i, posteriorment, es repeteix el 1382 (cf. Ch.-E. DufourCQ, Catalogue, pp. 140-141, doc. 267) i el 1392 (cf. M.T. FERRER, La frontera, p. 174).
} 
terme, Berenguer Mercader també havia acceptat, abans del trencament definitiu de les negociacions, consultar-ne el rei Alfons.

$\mathrm{Si}$, durant la pau, almogàvers granadins entraven al regne de València i captivaven algun cristià i se l'enduien a Granada o a qualsevol altre lloc sota jurisdicció del nassarita, Muhammad hauria de manar als alcaids de Vera i de Vélez el Mayor que capturessin els almogàvers i els donessin mort, i que, després, quan en fossin requerits, restituïssin al governador d'Oriola els cristians captius i totes les robes, béns i coses que els haguessin estat preses. Això mateix hauria de ser observat si almogàvers o altres persones catalanoaragoneses entraven a Granada, però aleshores hauria d'encarregar-se'n el governador d'Oriola ${ }^{63}$.

Com el precedent, aquest capítol dels almugàvers fou un altre dels que els nassarites posaven en qüestió però que, finalment, Berenguer Mercader s'havia mostrat disposat a revisar.

Qualssevol captius que ja aleshores, abans de la pau, i, en endavant, durant els dos anys de vigència d'aquesta, estiguessin en poder d'algun dels dos reis, haurien de ser deixats anar i deslliurats de captivitat, perquè poguessin tornar lliurement a les seves terres, o on volguessin, sense cap impediment.

Aquesta era, segons la carta de Berenguer Mercader, una de les principals innovacions del tractat de 1418 ja que, segons ell, mai cap rei d'Aragó no havia aconseguit l'alliberament dels captius reials sense pagament de rescat o sense bescanvi ${ }^{64}$. El valor que les autoritats catalanoa-

\footnotetext{
${ }^{63} \mathrm{El} 1405$ la clàusula és la mateixa, però preveu la possibilitat que puguin actuar, també, els lloctinents dels alcaids de Vera i de Vélez el Mayor o el del governador d'Oriola; $c f$. A GiMÉNEZ, La Corona de Aragón, "BRABLB" IV (1907-1908), pp. 360-361 (al capdavall de la p. 360, Giménez Soler transcriu $X$ anos en lloc de christianos, fet que indueix a confusió contrasteu-ho amb la transcripció que ofereix M. MASALA, Martino l'Umano, p. 330). La clàusula dels almogàvers havia estat introduïda per primer cop al tractat de 1382 ( $c f$. M.T. FERRER, La frontera, p. 165), i tornà a aparèixer al de 1392 (cf. ibidem, p. 174).

${ }^{64}$ Segons la treva de 1405 , per exemple, els captius que en el moment de la signatura de l'acord estaven en poder reial també havien de ser deslliurats, però contra pagament de 100 dobles per testa (cf. A. GIMÉnEZ, La Corona de Aragón, "BRABLB" IV (1907-1908), p. 360). Altres tractats també preveien l'alliberament dels captius, però no sempre disposem d'elements per dir en quines condicions; podem deduir, tanmateix, que, el 1382, la devolució havia de ferse per intercanvi (cf. M.T. FERRER, La frontera, p. 165), com el 1386 (cf. ibidem, pp. 169-170) i, probablement, el 1392 ( $c f$. ibídem, pp. 174-175). I, sabem, a més, que "Ali Abenramoní", el mateix ambaixador nassarita que estigué a Barcelona a la fi de 1409 i a l'inici de 1410 per negociar la pròrroga de la treva de 1405 amb el rei Martí i que llançà les proclames per incentivar l'emigració dels sarraïns cap a Granada, també havia estat enviat al rei Martí per Muhammad VII l'octubre de 1406 per tal de rescatar, almenys, cinc (cf. ibídem, pp. 181-182) i tretze ( $c f$. C. BARCELó, Minorías, p. 40, salconduït per anar a l'Alcúdia de Barbaria en favor
} 
ragoneses donaven a aquesta consecució del Magnànim també queda palès en el fet que la crida feta a València per publicar la treva ressaltés només que la treva era de dos anys i que "tots los catius christians qui són en poder del dit rey de Granada és tengut donar franchs al senyor rey". Això, a més, evidencia que, al marge del període de durada de la treva, que lògicament havia de fer-se públic, i del capítol dels captius, la resta de clàusules i condicions de l'acord es consideraven, des del moment que no calia destacarlos, els habituals. I, segons Berenguer Mercader, si Muhammad VIII es va negar a ratificar l'acord en els quinze dies que tenia per fer-ho fou, sobretot, "per sguart dels catius vassalls vostres que son en lo corral ${ }^{65}$ los quals en aquesta pau devien esser presentats franchs a vostra senyoria". Tot i que els captius granadins en poder d'Alfons el Magnànim també haguessin de ser alliberats francament, podria ser que el nassarita es negués a acceptar-ho pel fet que, segurament, els captius cristians que tenia el rei de Granada en poder seu devien ser molt més nombrosos que no pas els que devia tenir el monarca catalanoaragonès ${ }^{66}$.

d'Ali Albarramoni, sarraí de Granada, i del seu fill Abrafim, juntament amb tretze musulmans granadins rescatats a València a l'empara dels capítols de la treva) captius granadins, d'acord amb allò que preveia la treva signada poc abans, vigent des del mes de maig de 1405 . Ali anava acompanyat del seu fill Abrafim (cf. L. PILES, Estudio documental, doc. 40, p. 131) i probablement fou aleshores mateix que rebé llicència del rei Martí per endur-se'n amb ell cap a Granada un seu nebot, Çaat, amb la dona, Neyme -membres, segurament, de la branca valenciana de la seva família-, sense haver de pagar cap dret; ens n'informa una carta del mateix ambaixador que feia saber al rei que, en relació amb els captius que havia d'endur-se'n, no havia pogut acomplir tot allò que volia, perquè li convenia tornar immediatament a Granada, però que, al cap de pocs dies, si Déu i el rei ho permetien, tornaria a València o allà on fos el monarca, amb algun rescat, per endur-se'n més (ACA, C., CR Ferran I, caixa 10, núm. 1174. S.d. s.l.).

65"Corral" era el nom que els captius catalanoaragonesos $\mathrm{i}$ murcians donaven a les masmorres granadines on els sultans tenien empresonats els seus captius.

${ }^{66}$ Tant a Granada com als sultanats nordafricans una gran part dels captius eren retinguts en poder dels sultans en presons on la massificació i la consegüent necessitat de disciplina determinaven la duresa de les condicions de vida (vegeu M.T. FERRER I MALLOL, La redempció de captius a la Corona catalano-aragonesa, "AEM" 15 (1985), pp. 238 i 239, i R. SALICRÚ I LLUCH, Cartes de captius cristians a les presons de Tunis del regnat de Ferran d'Antequera. "MTM" 7 (1994), pp. 551-557). Si, a Granada, la Torre de los Picos de l'Alhambra fou, probablement, alçada pels captius cristians reials (vegeu J.M. de Cossío, Cautivos de moros en el siglo XIII, "AA" 7 (1942), pp. 80-81; R. ARIÉ, L'Espagne Imusulmane, pp. 321-322 i nota 1), cap a 1320, l'abdalwàdida Abu Tashfin també confessava a Jaume II que, a Tlemcèn (on, segons Ibn Kaldun, al segle XIV els esclaus s'hi comptaven a milers), totes les feines eren fetes per captius (vegeu-ho, per exemple, ibídem, pp. 321-322); es tracta d'una xifra potser exagerada, però no, necessàriament, esgarrifosa: a Tunis, el 1399, sembla que n'hi havia més de mil cinc-cents ( $c f$. D. GiRONa I Llagostera, Itinerari del rey en Marti (1396-1402), "Anuari de l'Institut d'Estudis Catalans" IV (1911-1912), pp. 81-184 i V (1913-1914), p. 142, núm. 30 [ACA, C., reg. 2242, f. 136v. 1399, abril, 17]). En terres catalanoaragoneses, els 
En canvi, els captius que, el 1418, estiguessin en poder de vasalls d'algun dels dos reis, només quedarien lliures previ pagament, per testa de captiu, de 100 dobles de bon or, de bona llei i de bon pes, franques de tot dret i despesa ${ }^{67}$.

En darrer terme, la treva de 1418 recull una clàusula del tot original, que només té paral·lel, que sapiguem, al tractat de $1392^{68}$, que fou d'on degué extreure-la Joan Mercader en redactar-la, i que va destinada a la indemnització de les preses marítimes. Conforma, puntualment i amb una finalitat molt concreta, una institució que presenta paral-lelismes amb la castellanogranadina de l'alcalde o jutge entre moros i cristians ${ }^{69}$, però que té, podríem dir-ne, un caràcter més corporatiu, perquè en lloc de preveure l'existència d'un sol jutge per cada regne en preveu dos.

El 1418 , la finalitat concreta de la clàusula era la de reintegrar totes les preses fetes "durant el tiempo de la çaguera paç que fue feyta entre-1 senyor rey, nuestro padre, de buena memoria, e el rey don Iucef, padre vuestro", és a dir, durant el període de vigència de la darrera pau signada per Ferran d'Antequera. Per tant, cal suposar que el text vol referir-se a la treva de 1416-1417 i a les preses fetes des de l'abril de 1416 fins a l'abril de 1417 , i no pas a la de 1415-1416. Perquè tot i que, en realitat, l'acord de 1416 fos, posteriorment, ratificat per Alfons el Magnànim, és, de fet, el darrer que Ferran I va signar.

Com el 1392, aquests jutges no havien de reunir-se ni a Granada ni a la Corona d'Aragó, ans en territori neutral, ço és, a la ciutat de Múrcia.

La clàusula preveia que totes les fustes, mercaderies, robes $i$ béns presos, de la manera que fos, durant el temps d'aquella treva, o llur valor

captius reials també podien anar a parar a les presons comunes, almenys mentre es decidia quin era el seu futur o la seva destinació, però, sempre. Iluny de la massificació (vegeu R. SAlicrú, Cartes, nota 31 ).

${ }^{67}$ Segons ja hem dit. el tractat de 1405 preveia que fossin els captius reials els que haguessin de pagar un rescat de 100 dobles d'or per testa, i no, com el 1418, els que estiguessin en mans dels seus súbdits. El 1405, els captius que estaven en poder dels vassalls del rei Marti i de Muhammad VII havien de rescatar-se contra pagament del preu de compra. Per evitar possibles fraus en el manifest dels captius i del seu preu veritable, l'acord de 1405 preveia, a més, que els dos monarques prohibirien que els captius canviessin de mans i fossin trets del regne on estiguessin, per tal que, un cop signada la pau, seguissin en poder de les mateixes persones $\mathrm{i}$ en les mateixes condicions que en el moment de la negociació de l'acord ( $f$. A. GIMÉNEZ, La Corona de Aragón, "BRABLB" IV (1907-1908), p. 360).

${ }^{68}$ Vegeu M.T. FERrer, La frontera, p. 174.

${ }^{(6)}$ Vegeu, fonamentalment, J. de M. CARRIAzo, Un alcalde; L. SECO DE LuCENA, El juez...; IDEM. Sobre el juez, i J. TORRES, El alcalde. 
i justa estimació, haguessin de ser restituïts a les persones a qui haguessin estat presos o robats, i a qui pertanyessin legítimament, durant el primer mig any que seguís al dia de la ratificació i aprovació de la treva per part del sultà nassarita. Amb la finalitat d'executar i de despatxar aquestes restitucions, es convingué que, abans de dos mesos des de la data de ratificació de la treva per part de Muhammad VIII, serien elegides quatre persones, dues per part d'Alfons i dues per part de Muhammad, que, conjuntament, rebrien informació per escrit, als regnes i terres de l'un i de l'altre, de les fustes, mercaderies, robes i béns que havien estat presos durant aquell any de treva. Després, aquestes quatre persones haurien d'aplegar-se a la ciutat de Múrcia, on jutjarien quins d'aquests béns havien de ser restituïts, a qui, per quin valor i quan, sense cap contradicció. Abans de procedir, els quatre jutges haurien de prometre $i$ jurar que es comportarien diligentment i sense cometre cap mena de frau. Alfons prometia que obligaria els seus súbdits a fer les restitucions, de manera que Muhammad pogués reintegrar fàcilment i sense dificultat els seus súbdits; i, en cas que hi hagués béns de vassalls catalanoaragonesos en poder de granadins, Muhammad també hauria d'obligar-los a fer-ne satisfacció quan i com les quatre persones esmentades ho decidissin. Per tant, símptoma de la corelació de forces, si bé es donava per segur que els súbdits catalanoaragonesos havien fet captures durant la treva, que ho haguessin fet alguns granadins es considerava, només, una possibilitat.

Segons el text registrat a la cancelleria catalanoaragonesa, Alfons atorgà, signà i lloà la pau, per dos anys, sota aquestes condicions i en nom de tots els seus súbdits, el dia 4 de juliol de 1418, a Saragossa. I l'endemà, 5 de juliol, ho féu, per part granadina, després que li fossin llegits de paraula i en arábico els capítols esmentats, Hayren o Hayrin, fill d'Hayrotla, cavaller enviat i procurador del rei de Granada. Amb poders de Muhammad VIII per fer i signar totes aquestes coses, en nom i com a missatger $i$ procurador seu, Hayrin també lloà i signà els capítols, per Muhammad VIII i per tots els seus vassalls. El poder i procura d'Hayrin constava en un document amb signatura autògrafa del rei de Granada atorgat $i$ datat el dia 25 del mes morisc anomenat arabi halau - primer de juny en el compto christianesco- de l'any 821 de l'era morisca. En virtut de tot això, Hayrin prometé que Muhammad observaria aquells capítols i que, abans de quinze dies des que un missatger d'Alfons hagués arribat a Granada, el sultà ratificaria, lloaria, signaria i juraria, amb carta pública, l'acord. 
Guerau Alamany de Cervelló, governador de Catalunya, Joan Martínez de Luna i Berenguer Bardaixí, consellers reials, actuaren com a testimonis de la signatura del rei Alfons. L'endemà, ho foren de la d'Hayrin, fill d'Hayrotla, Ramon Xatmar, Joan Dayuto, del regne de Sicília, Martí de Torres, Guillem Sànchez d'Algaraví, prior de la Penya, i Mahomat Huley Leix, Mahomat Emhegi i Mahomat Madrani, moros de la ciutat de Granada, que segurament formaven part de la comitiva de l'ambaixador. Actuà com a notari el secretari reial Paulo Nicolás.

Com de costum, Alfons féu redactar dos instruments públics iguals, deixant-hi en blanc l'espai on Hayrin pogués fer-hi escriure, en nom seu, els capítols en morisc i la signatura del rei de Granada. Una de les dues còpies havia de ser per Alfons i l'altra per Muhammad VIII.

Però, un cop a Granada, resultà, tot i que l'ambaixador nassarita ho negués i segons la versió tant de Muhammad VIII com del seu alcaid i algutzir major, Yamin, i de l'ambaixador d'Alfons, Berenguer Mercader, que els capítols que presentà aquest darrer no concordaven amb els que presentà Hayrin i que aquest, si havia signat les clàusules que Mercader assegurava però que ell negava, s'havia excedit en els poders, perquè havia anat més enllà d'allò que li atribuïa la seva procura.

Després de diverses confrontacions i acaraments, tant una part com l'altra es negaren a transigir i, mentre Hayrin era empresonat i posat en una sitja sota terra ${ }^{70}$, li eren confiscats tots els béns i roba de casa, i la seva

\footnotetext{
${ }^{70}$ Encara que el testimoni que en tenim faci referència a aquelles on eren tancats els captius cristians $i$ no pas els presoners musulmans com Hayrin. les presons granadines eren. generalment. ja a la fi del segle XIII. masmorres subterranies, de diversa profunditat (vegeu J.M. DE COSSíO. Cautivos. p. 74: M. GONZÁLEZ JiMÉnEZ. Esclanos andaluces en el Reino de Granada. dins La Sociedad Medieval Andalusa: Grupos no privilegiados. Actas del III Coloquio de Historia Medieval Andaluza. Jaén, noviembre 1982. Jaén, Instituto de Cultura de la Diputación Provincial, 1984. p. 337). i sembla ser que continuaren essent-ho fins a la fi del sultanat. Humides i fosques. estaven compartimentades en petites cel-les. Tres d'aquests soterranis de l'Alhambra - lloc on, justament, fou empresonat l'alcaid Hayrin-, que pogueren ser reconstruïts per Torres Balbás. disposaven de cel-les aptes per a acollir, cadascuna, onze. tretze o vint-i-sis presoners ( $c f$. R. ARIÉ. L'Essagne. p. 322; L. TORRES BALBÁS, Las mazmorras de la Alhambra, "AA" IX (1944. fascicle 1), pp. 198-218). Tanmateix, moltes vegades els calabossos podien ser. fins i tot. excavats a la roca viva, com en el cas de Màlaga. Ronda. Almeria o Comares (cf. R. ARIÉ. L'Espagne, p. 322 i nota 5, que refereix el testimon de Münzer). Loctubre de 1494, en visitar l'Álhambra. J. MüNZER, Viaje por España y Portugal. Madrid. Ediciones Polifemo. 1991. p. 93, descriu un $\|$ oc "que fue cárcel de los cristianos cautivos. Es un lugar espacioso. rodeado por un muro, () donde hay catorce profundas cuevas. muy estrechas por la parte alta. con un solo orificio, de mucha profundidad, y cavadas en la misma roca. En una de ellas venian a encerrar cien o doscientos cautivos": també en visitar Màlaga, ibídem. p. 145, parla de "tres cuevas o grandes oquedades cavadas en la durísima piedra, como están las de Granada. donde se custodiaban los cautivos cristianos".
} 
muller i els seus fills eren expulsats de l'Alhambra, Berenguer Mercader deixava transcórrer, sense resposta, els quinze dies aptes per a la ratificació del tractat i emprenia, seguidament, passant per Alcalá la Real, el camí de retorn cap a València.

Des d'aquesta localitat castellana, el 4 de setembre de 1418, escrivia llargament a Alfons el Magnànim per relatar-li la seva versió dels fets, mentre, a corre-cuita, seguint els seus passos, l'encalçava un altre ambaixador nassarita, vell conegut dels castellans perquè era qui havia negociat les treves de Ferran amb Yusuf III, Said al-Amin, que s'apressava per poder renovar la treva amb Castella abans que la ruptura de les negociacions amb la Corona d'Aragó no pogués tenir conseqüències negatives ${ }^{71}$.

Ben aviat, el març de 1419, Muhammad VIII el Petit seria destronat pel ja en endavant quasi permanent aliat d'Alfons el Magnànim, Muhammad IX l'Esquerrà. I en el que queda, des del setembre de 1418 en endavant, del seu regnat, ja no tenim constància de més contactes diplomàtics directes entre el Petit i Alfons.

Encara que, en notificar-li el fracàs de la treva i en exposar-n'hi els motius, Muhammad VIII hagués manifestat al Magnànim la seva voluntat que entre ells dos continués havent-hi "el grand amor e la bien querencia (...) entre nós e vós commo siempre fue"72, ni ells dos $^{73}$ ni, que sapiguem, cap dels futurs successors del nassarita ja no arribarien a concloure cap més tractat d'aquestes característiques.

Sabem, com he dit, que, a la dècada dels quaranta, Joan de Navarra, en nom del seu germà, instal·lat a Nàpols, aconseguiria que la Corona

\footnotetext{
"A. GimÉnez, La Corona de Aragón. "BRABLB" IV (1907-1908), pp. 370-372. [1418]. setembre, 4. Alcalà de Bençcọt [la Real]. De l'anada de Said al-Amin cap a Castella el setembre de 1418 també n' ha quedat constància. en una carta sense any però que ara és datable, en la credencial que li fou expedida el 8 de setembre. adreçada, sense que se'n doni el nom, a larquebisbe de Toledo, tal com destacà R. CASTRILlo MÁRQuez. Una carta granadina en el monasterio de Guadalupe. "AA" XXVI (1961). pp. 389-396 (vegeu-ho a R. SALICRÚ, El sultanat. p. 161).

72ACA. C.. Cartes Àrabs. caixa 6. núm. 108. 11418|. setembre. 4. Granada. ed. A GimÉnEz. La Corona de Aragón.... "BRABLB" IV (1907-1908), pp. 369-370. i R. SAlicrú. Relacions. vol. II, doc. 47.

${ }^{73}$ Muhammad VIII tornaria a regnar entre 1427 i 1430 . però en una conjuntura ja del tot diversa: $i$ per bé que. aleshores. el Magnànim mantingués amb ell una política oficialment amical, donà ple suport al seu rival. Muhammad l'Esquerrà, que s'havia refugiat a Tunis, perquè pogués tornar a la Península i disputar-li el tron. Vegeu-ho a R. Salicrú I Lluch, La Corona de Aragón y los nazaritas en el segundo reinado de Muhammad el Pequeño (1427. 1429). dins La frontera, pp. 199-211.
} 
d'Aragó i Granada tornessin a estar, altra vegada, oficialment en treva. Però ni s'ha conservat el text dels tractats, i per tant en desconeixem el contingut, ni hi ha cap mena de rastre de negociacions. Aleshores, aquests pactes, han de llegir-se sobretot com una expressió més de l'enfrontament amb Castella que es canalitzà a través del regne de Múrcia. I, aleshores, sobretot, ja s'havia operat el canvi en el model politicodiplomàtic i en la dinàmica de les relacions catalanoaragoneses amb Granada que descrivíem inicialment, canvi que es traduí en una mutació del valor que treves com la de 1418, que en podria ser el darrer testimoni, havien tingut fins aleshores per garantir l'estabilitat dels contactes.

\section{RÉSUMÉ}

Du règne d'Alphonse le Magnanime ne nous est parvenu qu une seule trêve avec Grenade, celle de 1418 qui n'entrera jamais en vigueur. Pendant le règne de Ferdinand d'Antequera, la Couronne d'Aragon n'était resté en relation avec Grenade que par des trêves sur le modèle castillan que Ferdinand signa au nom de Jean II de Castille et qui s’étendaient à la Couronne d'Aragon. Pour cette raison, la trêve de 1418 représente un notable effort de récupération de la tradition catalano-aragonaise, effort mené par le bailli générale du royaume de Valence. Joan Mercader, qui peut s'apprécier clairement quand on analyse un par un les articles de la trêve et que l'on les compare avec ceux des traités antérieurs.

\section{SUMMARY}

Only the text of a single truce with Granada, that of 1418 and which never came into force, has been preserved from the reign of Alphonso the Magnanimous. During the previous reign of Ferdinand of Antequera, the Crown of Aragon had remained bound to Granada by means of the Castilian model truces that Ferdinand of Antequera signed in name of Johan II of Castile and that were extended to the Crown of Aragon. For this reason, the truce of 1418 represents a remarkable effort for recovering the Catalano-Aragonese tradition, effort carried out by the general bailiff of the kingdom of Valencia, Joan Mercader, and that can be clearly appreciated when we analyze. one by one, all the chapters of this truce and we compare them with those of previous truces. 